\title{
ON THE ANALYSIS OF THE FACTOR OF RECALL IN THE LEARNING PROCESS.
}

\author{
BY EDWINA E. ABBOTT.
}

CONTENTS.

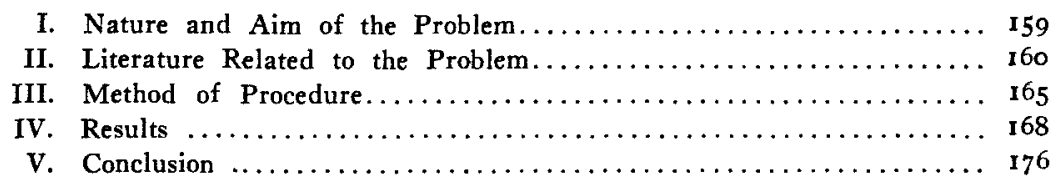

I. The Nature and Aim of the Problem.

No one who has had experience in memorizing or in watching others memorize can have failed to observe the tendency of the average person when he is reading, to momentarily turn away from the material before him and to repeat it to himself without external aid. This tendency to recall appears whatever may be the material which is to be memorized or to whatever sense it is presented. The learner will of ten go through this procedure even when he knows he cannot remember the whole accurately; or, if the material is easily grasped, after he is able to repeat it perfectly and before dismissing it from his attention, he will repeat it to himself two or three times. The fact that this tendency is to be observed, however, does not justify us in believing without further evidence that recall is a desirable and helpful factor in the learning process. For, if experimental results in the field of memory have demonstrated anything, it is that the average person is not sure to use in memorizing the best and most economical methods to help himself. It is only by careful investigation under all conceivable conditions that we may obtain any adequate idea of the use and relative value of these factors which appear in the mental habits of normal people.

Certain results obtained in an experiment ' On the Analysis of the Memory Function in Orthography ' ${ }^{1}$ conducted in the

${ }^{I}$ See paper in this monograph. 
psychological laboratory of the University of Illinois in the year $1907-08$, led to the conclusion that the opportunity for recall, during or immediately after the learning process, was of great benefit to the individual. It has been the aim of the present experiment to determine more carefully the nature of the influence of this recall and the conditions under which it could be used most favorably. In other words, to determine, when a definite length of time is given in which to learn a given amount of material, whether it is of the greater advantage to spend all the time in actual perception of the material, or part of the time in perception and part in recall; and also whether the recall should be interspersed with the perception or should follow it immediately or after an interval. We have also attempted to make some analysis and explanation of the factors which are of influence in this recall period and particularly to determine the effect of localization.

The work already done along the line of economy of learning has shown that the relative value of many of the so-called methods of learning depend in a large measure on the memory type of the individual who is to use the method. A condition which would be of great advantage to a visually-minded individual might prove positively distracting to one of the auditorymotor type and again might have no appreciable effect on the individual of a mixed type. In view of this, in the present experiment care was taken to determine from introspective analysis the type of imagery of the subjects and in general the mental processes which they went through in learning the material presented to them.

\section{Literature Related to the Problem.}

In the experiment under discussion the total time devoted to learning was divided into two equal periods and separated by varying intervals. This procedure relates itself to the experiment of Jost, ${ }^{2}$ who endeavored to verify the conclusions of Ebbinghaus. ${ }^{3}$ Ebbinghaus found that sixty-eight successive

'Die Assoziationfestigkeit in ihrer Abhängigkeit von der Verteilung der Wiederholungen,' Zeitschr. fur Psychol. u. Phys. d. S., XIV., 436-472 (1897).

${ }^{3}$ Ueber das Gedachtnis, Leipzig, 1885. 
repetitions of memory material have a less profitable effect than thirty-eight repetitions divided over three days. In his experiment Jost used the 'Esparnismethode' to determine whether there was greater or less advantage in presenting a series of twelve nonsense syllables thirty successive times, or in dividing the thirty repetitions equally over three days. His results showed that twenty-four hours after the final repetition there was more time saved in relearning when the first thirty repetitions had been divided. In an attempt to discover the reason for this superiority Jost investigated the laws of association by means of both the 'Treffer' and 'Esparnismethode' and comes to the following conclusions: First, that only the 'Treffermethode' can give a direct determination of the reproduction tendency of a series; second, that the two methods cannot give results at all comparable; third, that there are two fundamental laws of association as follows:

I. If two associations are of the same strength but of different age, a new repetition will have the greater value for the older one.

2. If two associations are of equal strength but of different age, the older one will decrease the less with time.

In all memory experiments in which the same material is presented repeatedly the factor of localization must enter to a greater or less degree. Pohlmann in experiments with school children and seminary students, in which nonsense material was presented with and without the opportunity for localization, concluded that this factor is an aid to memory and also that it is not necessarily of a visual character although apt to have more influence when of a visual nature.

The experiments of Witasek $^{4}$ and Katzaroff ${ }^{5}$ bear more directly on our problem. Their purpose was to determine the relative effect of recitation and reading. Witasek presented groups of ten nonsense syllables by means of Wirth's memory apparatus at the rate of one syllable per second. The subject read the syllables aloud in trochaic rhythm during those series

4 “ Über Lesen und Rezitieren in ihren Beziehungen zum Gedachtnis,' Zeitschr. für Psychol. u. Phys. d. S., XLIV., 161-246 (1907).

' 'Le rôle de la récitation comme facteur de la mémorisation,' Archives de Psy., VII. (Igo8). 
designated as ' reading-series.' During the 'recitation-series' the syllables were pronounced aloud and the subject attempted to keep the rhythm and tempo the same as in the reading series. When the syllable was forgotten the subject was given ten seconds in which to recall it. If he failed to recall it during this time, $E$ read the correct syllable to him and the recitation was resumed. When a wrong syllable was given the subject was stopped and the right one given him. The subjects were instructed never to go back over the syllables either during the reading or recitation series and to rule out associative links as far as possible. The order of series was as follows:

$\begin{array}{lrlcc} & \text { A. } & \text { B. } & \text { C. } & \text { D. } \\ \text { (a) } & \text { XVI } 5 & \text { VI o } & \text { XI ro } & \text { XV ro } \\ \text { (b) } & \text { XI } 5 & \text { VI 15 } & \text { VI } 5 & \text { XI } 0 \\ \text { (c) } & \text { XVI } 0 & \text { XI 15 } & \text { XX } 0 & \text { VI ro }\end{array}$

The Roman numerals indicate the reading series, the Arabic numerals the recitation series. A, B, C and D were alternated to eliminate practice effect. In every case ten 'test-recitations' were given one hour after the completion of a series. A record was kept of the time consumed by every recitation and also of the helps given in the course of every recitation. From these data the following conclusions are drawn:

I. Recitations are in general far superior to readings in learning value.

2. Of recitation groups following one another the first has the greatest learning value and each succeeding group has less.

3 . Of readings following one another the first has the greatest learning value and each succeeding reading has less.

4. The learning value of a recitation is higher if the association by which it is strengthened is made not through single readings but through reading and recitation.

Katzaroff used in his experiment the 'Treffermethode.' He presented groups of eight or ten pairs of nonsense syllables on a revolving drum which showed each couple for two seconds. Successive readings were separated by an interval of four seconds. During the presentation the subject was required to read the series aloud in trochaic rhythm. He was not to create artificial associations. During the recitation the first syllables 
of every couple were presented in a different order from that of the reading presentation. The subject gave the corresponding syllable as quickly as possible. If he was unable to recall it or gave it wrongly, the right one was given to him. The series were presented with the following combinations of readings and recitations. The column to the left indicates the number of 'fundamental readings'; $L$ signifies reading and $R$ signifies recitation. The small number indicates the number of successive readings or recitations in a group.

\begin{tabular}{|c|c|c|c|}
\hline L 10 & interval of 2 minutes & $\operatorname{Rx} L_{5}$ & 48 hours. \\
\hline L ro & interval of 2 minutes & $R_{1} R_{5}$ & 48 hours. \\
\hline L 8 & interval of 2 minutes & $L_{7}$ & 72 houts. \\
\hline L 8 & interval of 2 minutes & $\mathbf{R}_{7}$ & 72 hours. \\
\hline L 8 & interval of 2 minutes & $\mathrm{I}_{7}$ & 72 hours. \\
\hline L 8 & interval of 2 minutes & Rr L6 & 72 hours. \\
\hline L 4 & interval of 2 minutes & L6 & 24 hours. \\
\hline$L_{4}$ & interval of 2 minutes & R6 & 24 hours. \\
\hline $\mathrm{L}_{4}$ & interval of 2 minutes & RI LI RI LI RI LI & 24 hours. \\
\hline$L_{4}$ & interval of 2 minutes & L6 & 24 hours. \\
\hline L 4 & interval of 2 minutes & $\mathrm{R}_{3} \mathrm{~L}_{3}$ & 24 hours. \\
\hline $\mathrm{L}_{4}$ & interval of 2 minutes & $R_{2}$ LI RI LI RI LI & 24 hours. \\
\hline
\end{tabular}

Katzaroff concludes that:

I. All the experiments show $R$ superior to $L$ in conservation, promptness and certainty of memory; we are justified in concluding that after a certain number of fundamental readings the recitation has a fixing value superior to that of an ordinary reading.

2. The extent of R's superiority varies according to the number and disposition of $\mathrm{R}$ in relation to $\mathrm{L}$. The best combination appears to be a number of fundamental L's proportioned to the length of the series. Then at least two R's, then at least two L's to reinforce the series as a whole.

Katzaroff explains his results: first, by the fact that the mental attitude in recitation is active and one of constantly looking forward and never looking back, while in reading the attitude is passive, thus making recitation more favorable for the factors 
of attention and the richness of association; and second, from the point of view of the cerebral force. The neural paths which are traced in the trial recitations are the same as those used in the final recitation. The centers and paths used in reading are not the same.

Meumann ${ }^{6}$ has noted this natural tendency, referred to above, to make use of an immediate recall in connection with the learning process. In treating that phase of memory which constitutes the attentive impressing on the mind of sensory data, he states that " all sense impressions go through a double period of forgetting. The first is, in a measure, only a fading of the original impression and during this period the impression will be reproduced most easily and similarly will be most easily made enduring by a repetition of the stimulus. Therefore we see that it is important for the technique of the learning of sensory material that the active impression be made while the stimulus is still present or immediately thereafter. We proceed thus unconsciously when we wish to make a lasting impression on our minds of some complicated material. We reproduce it while the object is still before us or we close our eyes a moment and then bring our attention back to the object after we have endeavored to reproduce it unaided."

It is obvious that Witasek and Katzaroff in introducing recitation into their period of recall made of it an entirely different process from that described by Meumann. The factor emphasized by Katzaroff in his explanation of the efficacy of recitation is the attitude of 'never looking back and constantly looking forward.' This factor is in direct opposition to that of 'immediate imaging' by which Meumann explains the value of immediate recall. Since it is obvious that both these factors cannot enter at once into the mental process of a subject who is given an opportunity for immediate recall, the question remains, which factor is used when the subject is left free to use the recall period as he likes and which is of the greater value for learning. It shall be our purpose to show that the use and relative efficiency of these factors depend on the memory type of the individual who is doing the learning.

${ }^{\circ} \ddot{O}$ konomie und Technik des Gedachtnisses, Leipzig, 1903. 


\section{Method of Procedure.}

The method used in conducting the present experiment differs in a few particulars from that used in preceding experiments bearing on the same problem. Other experimenters have required their subjects to make their recall entirely in the form of recitation. This would necessarily bring the vocal and auditory factors into strong prominence with all subjects and the results would in all probability be influenced by the individual type of the subjects. Since it was the purpose of the experiment under discussion to discover the factor or group of factors to which the influence of the recall period might be traced, the subjects were given the time for recall without directions as to how it should be used and through introspection the attempt was made to discover the factors present.

Katzaroff in his experiment on the influence of recitation used the 'Treffermethode,' that is, he presented nonsense syllables in pairs for the learning series, and for the recitation and recall series he presented only the first of each pair and the subject was instructed to give the accompanying syllable. It would appear that in seeking for the accompanying syllable the subject has two distinct courses open to him. He may remember it by means of its association with the syllable he is looking at; or he may remember it by some association in the column of syllables to be recalled. Since these two courses may introduce a complexity of factors into the recall we preferred to use in our experiment the more simple method of recalled members.

The most noticeable difference in our method from that of other investigators lies in the fact that in no other experiment has there been any definite attempt to determine the individual type of the subjects and to use this knowledge in the interpretation of the numerical results. So much has been said and will appear later concerning the importance of this knowledge that it is sufficient to state here that throughout our experiment this determination has been done in the case of every subject with the greatest care.

The material used in the experiment was of two kinds, nonsense syllables and words. The nonsense syllables were made up according to the method of Müller and Schumann and pre- 
sented in groups of thirty. The words were chosen at random from an English dictionary and included nouns, verbs and adjectives. They were never over four syllables in length. They were presented in groups of sixty. Both words and syllables were typewritten in columns on sheets of thin white cardboard and were so spaced that when the cardboard was fitted into the slide of a 'Jastrow fall shutter,' the words or syllables were exposed before a narrow opening, either one immediately after the other, or with a blank interval between. This fall apparatus was fitted with an electro-magnetic release. The electric circuit which controlled the falling shutter contained a mechanical interrupter or contact mechanism in the form of a toothed wheel. By the introduction of wheels of different forms, containing different numbers of teeth and different distances between the teeth, it was possible to vary the temporal relation of the exposure at will. Thus the stimulus word or syllable could be exposed for one second with an interval of three seconds or with no interval. This mechanical interrupter was in turn controlled by an electric pendulum (Zimmermann's Kontaktuhr). The word or syllable when it was exposed on the shutter was reflected through a lens onto a ground glass screen in a large camera-shaped box. At the end of the box opposite the lens was an opening of a convenient size and the subject sat before the box with his eyes on a level with this opening. The box was so made that the focus could be adjusted for any individual. The system of lenses had a diameter of five centimeters and a focal length of thirty-two centimeters.

It will be seen from the table on page ${ }^{6} 7$ that in series $a, b$, $c, d, e, f, h, i$ and $j$, sixteen minutes were devoted to the entire process of learning, while $g$ and $\mathrm{k}$ received only eight minutes. Also that in the series $\mathrm{a}, \mathrm{b}, \mathrm{c}$ and $\mathrm{g}$ there is no opportunity given for recall, the learning periods being consumed in Einprägung; that in series $\mathrm{d}$, e and $\mathrm{f}$ half the time is given to recall and it comes after the Einprägung and that in series $\mathrm{h}, \mathrm{i}, \mathrm{j}$ and $\mathrm{k}$ three fourths of the time is given to recall and it is interspersed with the Einprägung during the three seconds interval between presentations.

These series were presented in two different ways. The 
first way, which we have termed the 'regular order,' consisted in keeping the order of words or syllables in a group constant throughout the presentation time. The second way, termed the 'mixed order,' differed from the former in that a group of words or syllables was never presented twice in the same order.

The groups of words and syllables were presented in eleven different kinds of series as follows:

\begin{tabular}{|c|c|c|c|c|c|}
\hline Series. & $\begin{array}{l}\text { First } 8 \text { min- } \\
\text { utes spent } \\
\text { in }\end{array}$ & $\begin{array}{l}\text { Exposure } \\
\text { time per word } \\
\text { or syllable. }\end{array}$ & $\begin{array}{l}\text { Interval be- } \\
\text { tween words } \\
\text { or syllables. }\end{array}$ & $\begin{array}{l}\text { Interval be- } \\
\text { tween ist and } \\
\text { od learning } \\
\text { period. }\end{array}$ & $\begin{array}{l}\text { Second } 8 \text { min- } \\
\text { utes spent in }\end{array}$ \\
\hline a & $\begin{array}{c}\text { visual Ein- } \\
\text { prägung }\end{array}$ & $1^{\prime \prime}$ & o & $I^{\prime}$ & Einprägung \\
\hline b & 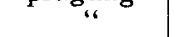 & $\mathrm{I}^{\prime \prime}$ & o & $15^{\prime}$ & " \\
\hline c & ،. & $I^{\prime \prime}$ & 0 & $45^{\prime}$ & “ \\
\hline $\mathrm{d}$ & " & $\mathrm{I}^{\prime \prime}$ & o & $\mathbf{I}^{\prime}$ & Recall \\
\hline e & ““ & $r^{\prime \prime}$ & 0 & $15^{\prime}$ & “ \\
\hline $\mathrm{f}$ & "6 & $\mathrm{I}^{\prime \prime}$ & 0 & $45^{\prime}$ & "6 \\
\hline g & “ & $1^{\prime \prime}$ & $\circ$ & & \\
\hline $\mathrm{h}$ & $\begin{array}{l}\text { Einprägung } \\
\text { and recall }\end{array}$ & $\mathbf{I}^{\prime \prime}$ & $3^{\prime \prime}$ & $I^{\prime}$ & $\begin{array}{l}\text { Einprägung } \\
\text { and recall }\end{array}$ \\
\hline ì & " & $1^{\prime \prime}$ & $3^{\prime \prime}$ & $15^{\prime}$ & " \\
\hline j & “" & $I^{\prime \prime}$ & $3^{\prime \prime}$ & $45^{\prime}$ & “، \\
\hline $\mathrm{k}$ & ، & $\mathrm{I}^{\prime \prime}$ & $3^{\prime \prime}$ & & \\
\hline
\end{tabular}

In both series the final recall was made four hours after the learning was completed. The subject was required at this time to write down all the words and syllables he could remember. He was given fifteen minutes for each group and at the end of that time those correctly recalled were counted and recorded. Only one group of words was given during one day to each subject. The series were not given in the order described, but in such an order that practice effect would be equally distributed for the three different sorts of series; that is, for the $a, b, c$ group, in which there was no opportunity for recall, the $d, e, f$ group in which the recall all came after the Einprägung and the $\mathrm{h}, \mathrm{i}, \mathrm{j}$ group in which the recall was interspersed with the Einprägung. During the one, fifteen and forty-five-minute intervals the subjects were not allowed to

' 'Einpragung' is the German word which designates the process of attending to sensory materials with a view to remembering it. There is no term in English which so aptly describes the process, and we have used the term 'visual Einprägung' to designate the time spent by our subject in attending to material visually presented with the view to remembering it. 
think of the material. The fifteen and forty-five-minute intervals were usually consumed in taking other groups or in presenting groups to another subject.

The subjects were given certain instructions. During the presentation of the groups in series $\mathrm{a}, \mathrm{b}, \mathrm{c}, \mathrm{d}, \mathrm{e}, \mathrm{f}$ and $\mathrm{g}$ the subject was not to form any associative links between the words or syllables and while one word or syllable was before him he was not to think of any other. We endeavored in this way to prevent as far as possible any attempt at reimaging. During the recall period in the $\mathrm{d}$, e, $\mathrm{f}$ series the subject was allowed to recall the group in any terms of imagery he wished and to associate the words or syllables in any way he wished. But he was not allowed to pronounce them aloud or to write them down. The recall period of three seconds in series $h, i, j$ and $k$ the subject was allowed to spend as he wished, and also in these series he was allowed to form any associations he wished to between the different members of the group. He was also instructed not to think of the material during the period between the learning and the final recall.

Throughout the experiment careful introspections were taken of the processes and imagery used both in the learning and recall. These were supplemented by questions from the experimenter with the particular object in mind of throwing light on the individual type of the subject. The subjects were students from the psychological laboratory at the University of Illinois and were five in number.

\section{Results.}

\section{Introspective Results.}

The numerical data when interpreted in the light of the introspective results take on an entirely new significance from that which appears when they are studied by themselves. Hence it is of the greatest importance before presenting the actual results of the experiment, to give a complete description of the type of procedure of each individual as it has been disclosed by means of the subject's own analysis. The procedure in the case of Einprägung seems to differ very slightly for all 
the subjects. They all look at the word or syllable attentively. Most of them are conscious of whispering the word or of employing 'inner-speech.' One of a marked visual type, however, repeatedly asserts that she is unconscious of any pronunciation whatever. She simply 'looks at the word and lets it soak in.' When one word passes from the field, the attention is focused on the next that appears.

When we come to the recall in the $d, e, f$ series, in which half the total learning time is given for recall and comes after the presentation is completed, we find that each individual constructs what he can of the group in terms of imagery most natural to him and then spends the remaining time reimaging and in forming more or less artificial associative links between the words or syllables. It is significant that these links are said to be formed after the first reimaging. The only exception in this general course of procedure is found in the case of $Y$ (strong visual type), who merely reimages repeatedly and does not form associative links between the words or syllables.

It is when we come to the $h, i, j$ group, in which the recall is interspersed with the Einprägung that we find the greatest deviation in general procedure. Four of the subjects spend the interval of three seconds of recall after each term of the group in thinking of the term which has been seen, in reimaging it according to their several types, in imaging some concrete object, perhaps sometimes in running back over the last two or three terms seen. For these cases the procedure is clearly that described by Meumann and referred to earlier, namely, that of catching the image just as it is fading from consciousness after the actual presentation, when it may most easily and most accurately be revived, and impressing it upon the mind. During this period there are also to some extent associative links formed, such as words and phrases which fit together by meaning, or rhyme or jingle. These are repeated together and they thus fall into groups. This associative tendency we find lacking, however, in subject $Y$. This subject reimages the last term usually and with few exceptions in concrete visual form, but there is little or no association between terms. Entirely different from this kind of procedure is that of the fifth subject, 
$W$, whose introspections follow in his own words. "The process of learning in this kind of a series is thus,-The first time the list of words is seen for each word, some image is called up and connected with the image of the next word. The word is also pronounced. After the first presentation, as soon as one word has disappeared I try to think of the next word. If I can, I say it over to myself. If not, I wait for it attentively. I put equal time on every word, for I never run back or forward in groups but always think of the word which is to follow immediately. The process is the same for the syllables, except that there is no concrete imagery for them outside the visual imagery of the syllable itself. These are sometimes spelled through and sometimes pronounced." This method of learning was possible only in the 'regular order.' In the 'mixed order' this subject reimaged the last word presented just as the other did. It will easily be seen that in the 'regular order' series this subject does not use at all the immediate reviving of the image of the term just seen, which revival is of such importance to the others. He has literally transformed the recall series into a recitation series such as those used in the experiments of Katzaroff and Witasek, the only difference being that he 'recites' in the imagery which he is most accustomed to using in his thinking, instead of in vocal and auditory terms, which he may or may not be accustomed to using. These general distinctions given, we will present the more detailed descriptions of the individual type of the five subjects and their procedure in the different kinds of series.

$V$. This subject makes use both of 'inner-speech' and concrete visual imagery in his thinking. In the $a, b, c$ and $g$ series, when there is no chance to think the words together, he pronounces them and looks at them attentively while they are being presented. Sometimes the concrete visual appears. In the final recall there is an attempt to revive whatever imagery there may be left of the word or syllable, but the subject seems to have poor control over this imagery. When trying to recall, he feels that the words are there and that they would be recognized instantly if presented. They seem to be just on 
the threshold, but there is nothing to get hold of them with. There is no handle. The predominant character of this imagery seems to be visual. "There seems to be a visual image," he says, "but it is one that moves very fast and there is not time to get any one word." Again, "In all cases of the mixed order the visual image of the word is used exclusively. The word is always pronounced when seen but this seems to be no aid in final recall." During the recall period in the $d, e, f$ series, the subject states that the visual image and inner pronunciation of those terms of the group which are recalled, appear simultaneously and all the terms which can be recalled are then linked together by some meaningful association. The process in the $\mathrm{h}, \mathrm{i}, \mathrm{j}$ and $\mathrm{k}$ series has already been described. It would appear then that the general character of $V^{\prime} s$ imagery is visual and also that the mere mechanical reproduction of sensory data in terms of imagery is difficult for him.

$W$. This subject is of a distinct verbal type. We do not find the concrete entering to a marked degree and when it does it appears to accompany and not aid either the learning or recall. This verbal imagery is motor-auditory and the Einprägung of a word or syllable is always accompanied by pronunciation. The imagery used in the recall period is decidedly of a mixed type and is in the main verbal. The process of learning seems to be one of reinforcing the verbal impression with various kinds of imagery, occasionally associating it with some concrete image or with some other word or syllable in the series and usually localizing it in the series either visually or by motor aid.

$X$. This is a subject who is predominantly motor-auditory, but who also uses visual imagery to a large extent. In the $h, i, j$ series the recall interval is used for repeating the term last seen and 'so fixing it in my mind.' Visual localization is employed frequently and if the first term of a column is gone, the other terms in that column are often lost entirely.

$Y$. This subject is of a very strong visual type who 'never pronounces a word or syllable in learning, merely tries to absorb the visual picture.' Concrete visual imagery also appears often. The words and syllables suggest these concrete images, but are 
rarely linked with other words or syllables in the group. During the recall period the last term seen is visualized and sometimes the last several terms are run over. In the final recall the subject remembers them 'by seeing them in the mind and remembering them as they appear on the screen.' The 'mixed order' impressed this subject as being particularly unfavorable. The concrete visual appears much more in evidence in the ' mixed order,' as the serial localization is inhibited.

$Z$. This subject was given only a few series, to determine if possible the effect of localization, and is a remarkably clear case of the necessity for introspective evidence as a means of interpreting objective results. The procedure was as follows:

For the mixed order the words are classified according to meaning and syllables according to resemblance and "the whole feeling is one of trying to get them through as many of the senses as possible." Concrete imagery rarely enters, although it sometimes does and is always a help when it does.

In the regular order all these aids are thrown overboard completely and a visual map of the card is made. In the recall visual imagery is used exclusively. These results show how completely the change of one objective factor may change the entire mental attitude with which the subject attacks the problem and cause entirely new processes to be used. It is folly to suppose that our mental processes are made up of factors which bear a definite relation point for point to the objective factors of the experiment and that by changing one objective factor we will merely change a corresponding factor or group of factors in the mental process. On the contrary we may by that one objective change substitute an entirely new set of factors in the mind of the subject.

\section{Objective Results.}

The tables below are given in terms of the per cent. of correctness.

Table I. presents the various series as described above for both the regular and the mixed order. The subjects tested are indicated at the right, each subject being tested on both words and syllables, and subjects $W, Y$ and $Z$ are tested for both the regular and the mixed order. 
FACTOR OF RECALL IN THE LEARNING PROCESS.

TABLE I.

\begin{tabular}{|c|c|c|c|c|c|c|c|c|c|c|c|c|}
\hline \multirow{2}{*}{ Series. } & \multicolumn{11}{|c|}{ Regular Order. } & \multirow{2}{*}{ Subject } \\
\hline & a & b & c & d & e & $f$ & $\mathrm{~g}$ & h & i & $\mathbf{j}$ & $\mathbf{k}$ & \\
\hline $\begin{array}{l}\text { Words } \\
\text { Syllables }\end{array}$ & $\begin{array}{l}23 \\
42\end{array}$ & $\begin{array}{l}23 \\
38\end{array}$ & $\begin{array}{l}24 \\
40\end{array}$ & $\begin{array}{l}23 \\
35\end{array}$ & $\begin{array}{l}33 \\
40\end{array}$ & $\begin{array}{l}25 \\
17\end{array}$ & $\begin{array}{l}23 \\
22\end{array}$ & $\begin{array}{l}4 I \\
68\end{array}$ & $\begin{array}{l}59 \\
92\end{array}$ & $\begin{array}{l}42 \\
70\end{array}$ & $\begin{array}{r}8 \\
47\end{array}$ & $V$ \\
\hline $\begin{array}{l}\text { Words } \\
\text { Syllables }\end{array}$ & $\begin{array}{r}8 \\
20\end{array}$ & $\begin{array}{r}8 \\
15\end{array}$ & $\begin{array}{l}\text { I3 } \\
\text { I2 }\end{array}$ & $\begin{array}{l}29 \\
20\end{array}$ & $\begin{array}{l}\text { I } 2 \\
30\end{array}$ & $\begin{array}{r}8 \\
27\end{array}$ & 5 & $\begin{array}{l}97 \\
97\end{array}$ & $\begin{array}{l}98 \\
97\end{array}$ & $\begin{array}{l}97 \\
98\end{array}$ & $\begin{array}{l}62 \\
62\end{array}$ & $W$ \\
\hline $\begin{array}{l}\text { Words } \\
\text { Syllables }\end{array}$ & $\begin{array}{l}15 \\
13\end{array}$ & $\begin{array}{l}28 \\
13\end{array}$ & $\begin{array}{l}23 \\
22\end{array}$ & $\begin{array}{l}28 \\
22\end{array}$ & $\begin{array}{l}15 \\
17\end{array}$ & $\begin{array}{l}18 \\
18\end{array}$ & $\begin{array}{r}13 \\
5\end{array}$ & $\begin{array}{l}3 \mathrm{I} \\
30\end{array}$ & $\begin{array}{l}34 \\
27\end{array}$ & $\begin{array}{l}30 \\
48\end{array}$ & $\begin{array}{l}\text { I8 } \\
\text { 10 }\end{array}$ & $X$ \\
\hline $\begin{array}{l}\text { Words } \\
\text { Syllables }\end{array}$ & $\begin{array}{l}67 \\
67\end{array}$ & $\begin{array}{l}78 \\
53\end{array}$ & $\begin{array}{l}83 \\
70\end{array}$ & $\begin{array}{l}48 \\
67\end{array}$ & $\begin{array}{l}42 \\
63\end{array}$ & $\begin{array}{l}43 \\
50\end{array}$ & $\begin{array}{l}28 \\
57\end{array}$ & $\begin{array}{l}53 \\
63\end{array}$ & $\begin{array}{l}55 \\
67\end{array}$ & $\begin{array}{l}\text { I7 } \\
53\end{array}$ & $\begin{array}{l}23 \\
43\end{array}$ & $\boldsymbol{Y}$ \\
\hline \multirow[t]{2}{*}{$\begin{array}{l}\text { Words } \\
\text { Syllables }\end{array}$} & $\begin{array}{l}54 \\
60\end{array}$ & & & $\begin{array}{l}6 \mathrm{I} \\
5 \mathrm{O} \\
\end{array}$ & & & & $\begin{array}{l}56 \\
55 \\
\end{array}$ & & & & $Z$ \\
\hline & \multicolumn{11}{|c|}{ Mixed Order. } & \\
\hline $\begin{array}{l}\text { Words } \\
\text { Syllables }\end{array}$ & $\begin{array}{l}\text { 1o } \\
\text { 17 }\end{array}$ & $\begin{array}{l}\text { I3 } \\
23\end{array}$ & $\begin{array}{l}17 \\
27\end{array}$ & $\begin{array}{l}13 \\
40\end{array}$ & $\begin{array}{l}12 \\
20\end{array}$ & $\begin{array}{r}7 \\
\mathbf{1} 7\end{array}$ & & $\begin{array}{l}20 \\
10\end{array}$ & $\begin{array}{l}\text { I } 7 \\
13\end{array}$ & $\begin{array}{l}8 \\
7\end{array}$ & & $W$ \\
\hline $\begin{array}{l}\text { Words } \\
\text { Syllables }\end{array}$ & $\begin{array}{l}28 \\
67\end{array}$ & $\begin{array}{l}25 \\
\text { ro }\end{array}$ & $\begin{array}{l}20 \\
40\end{array}$ & $\begin{array}{l}33 \\
40\end{array}$ & $\begin{array}{l}17 \\
37\end{array}$ & $\begin{array}{l}17 \\
20\end{array}$ & & $\begin{array}{l}27 \\
30\end{array}$ & $\begin{array}{l}18 \\
43\end{array}$ & $\begin{array}{l}27 \\
37\end{array}$ & & $Y$ \\
\hline $\begin{array}{l}\text { Words } \\
\text { Syllables }\end{array}$ & $\begin{array}{l}55 \\
52\end{array}$ & & & $\begin{array}{l}49 \\
68\end{array}$ & & & & $\begin{array}{l}53 \\
62\end{array}$ & & & & $\mathcal{Z}$ \\
\hline
\end{tabular}

TABLE II.

\begin{tabular}{|c|c|c|c|c|c|c|c|}
\hline Series & a & $\mathrm{b}$ & c & d & e & $f$ & Subject. \\
\hline $\begin{array}{l}\text { Words } \\
\text { Syllables }\end{array}$ & $\begin{array}{r}0 \\
20\end{array}$ & $\begin{array}{r}0 \\
16\end{array}$ & $\begin{array}{r}x \\
I 8\end{array}$ & $\begin{array}{r}0 \\
13\end{array}$ & $\begin{array}{l}\text { Io } \\
\text { I8 }\end{array}$ & $\begin{array}{r}2 \\
-5\end{array}$ & $V$ \\
\hline $\begin{array}{l}\text { Words } \\
\text { Syllables }\end{array}$ & $\begin{array}{r}3 \\
12\end{array}$ & $\begin{array}{l}3 \\
7\end{array}$ & $\begin{array}{l}8 \\
4\end{array}$ & $\begin{array}{l}24 \\
\text { I } 2\end{array}$ & $\begin{array}{r}7 \\
22\end{array}$ & $\begin{array}{r}3 \\
19\end{array}$ & $W$ \\
\hline $\begin{array}{l}\text { Words } \\
\text { Syllables }\end{array}$ & $\begin{array}{l}2 \\
8\end{array}$ & $\begin{array}{r}15 \\
8\end{array}$ & $\begin{array}{l}\text { Io } \\
17\end{array}$ & $\begin{array}{l}\text { I } 5 \\
\text { I } 7\end{array}$ & $\begin{array}{r}2 \\
12\end{array}$ & $\begin{array}{r}5 \\
13\end{array}$ & $x$ \\
\hline $\begin{array}{l}\text { Words } \\
\text { Syllalbes }\end{array}$ & $\begin{array}{l}39 \\
\text { I0 }\end{array}$ & $\begin{array}{r}50 \\
-4\end{array}$ & $\begin{array}{l}55 \\
13\end{array}$ & $\begin{array}{l}20 \\
10\end{array}$ & $\begin{array}{r}\mathrm{I} 4 \\
6\end{array}$ & $\begin{array}{r}15 \\
-7\end{array}$ & $\boldsymbol{Y}$ \\
\hline
\end{tabular}

Table II. was derived from Table I. by substracting the results obtained in series $\mathrm{g}$, from the results obtained in series $a, b, c, d$, e and $f$, respectively. This second table, therefore, represents what is gained by the added eight minutes of learning or recall over the time taken for the simple Einprägung. In some instances there is a minus quantity. Only the regular order was so treated.

Table III. gives the results of the words and syllables combined, as shown separately in Table I., but for the regular order only. 
Table IV. gives a comparison of the regular and of the mixed order for syllables and words combined and was derived from Table I. The letter $T$ in Tables III. and IV. indicates the average of the totals for $a, b$ and $c ; d, e$ and $f$; and $h, i$ and $\mathrm{j}$, respectively.

TABLE III.

\begin{tabular}{|c|c|c|c|c|c|c|c|c|c|c|c|c|c|c|c|}
\hline Series. & a & $b$ & c & $T$ & a & e & $f$ & $\mathrm{~T}$ & h & i & $\mathbf{j}$ & $\mathrm{T}$ & g & $\mathbf{k}$ & Subject. \\
\hline & 29 & 28 & 29 & 29 & 27 & 35 & 22 & 29 & $5^{\circ}$ & 70 & $5 \mathrm{I}$ & 56 & 23 & 21 & $V$ \\
\hline & 12 & II & 12 & I I & 26 & 18 & I4 & Ig & 97 & 98 & 97 & 97 & 6 & 62 & $W$ \\
\hline & 14 & 23 & 23 & 20 & 26 & I6 & 18 & 20 & $3 I$ & 32 & 36 & 35 & ro & I6 & $X$ \\
\hline & 67 & 70 & 79 & 72 & 54 & 49 & 46 & 49 & 57 & 59 & 29 & 48 & $3^{8}$ & 30 & $Y$ \\
\hline
\end{tabular}

TABLE IV.

\begin{tabular}{|c|c|c|c|c|c|c|c|c|c|c|c|c|c|}
\hline & a & $\mathrm{b}$ & c & $\mathbf{T}$ & d & e & f & $T$ & $\mathbf{h}$ & $\mathbf{i}$ & j & $\mathrm{T}$ & Subject. \\
\hline $\begin{array}{l}\text { Regular order } \\
\text { Mixed order }\end{array}$ & $\begin{array}{l}12 \\
12\end{array}$ & $\begin{array}{l}\text { II } \\
\text { I7 }\end{array}$ & $\begin{array}{l}12 \\
20\end{array}$ & $\begin{array}{l}\text { II } \\
\text { I6 }\end{array}$ & $\begin{array}{l}26 \\
22\end{array}$ & $\begin{array}{l}18 \\
14\end{array}$ & $\begin{array}{l}14 \\
10\end{array}$ & $\begin{array}{l}\text { I9 } \\
\text { I5 }\end{array}$ & $\begin{array}{l}97 \\
17\end{array}$ & $\begin{array}{l}98 \\
16\end{array}$ & 87 & $\begin{array}{l}97 \\
13\end{array}$ & $W$ \\
\hline $\begin{array}{l}\text { Regular order } \\
\text { Mixed order }\end{array}$ & $\begin{array}{l}67 \\
4 I\end{array}$ & $\begin{array}{l}70 \\
5 \circ\end{array}$ & $\begin{array}{l}79 \\
27\end{array}$ & $\begin{array}{l}72 \\
39\end{array}$ & $\begin{array}{l}54 \\
36\end{array}$ & $\begin{array}{l}49 \\
23\end{array}$ & $\begin{array}{l}46 \\
18\end{array}$ & $\begin{array}{l}49 \\
26\end{array}$ & $\begin{array}{l}57 \\
28\end{array}$ & $\begin{array}{l}57 \\
27\end{array}$ & $\begin{array}{l}29 \\
30\end{array}$ & $\begin{array}{l}48 \\
28\end{array}$ & $Y$ \\
\hline $\begin{array}{l}\text { Regular order } \\
\text { Mixed order }\end{array}$ & $\begin{array}{l}56 \\
54\end{array}$ & - & - & & $\begin{array}{l}57 \\
56\end{array}$ & - & - & & $\begin{array}{l}56 \\
56\end{array}$ & - & - & - & $Z$ \\
\hline
\end{tabular}

In comparing the efficiency of memory for words and syllables, we would expect for several reasons to find the syllables possessing an advantage over the words. Inasmuch as the groups of words were twice as great in number as the groups of syllables and the time of presentation was constant, each group of syllables was actually presented twice as many times as its corresponding group of words. The syllables, too, are shorter and simpler to perceive. In general we find the objective results (Table I.) show that this advantage exists for the syllables. The exception we find where we would expect to, namely, in the results of $W$ for the h, i and j series, where imagery played an insignificant rôle in the learning process. We would also expect that this superiority would be most marked in the case of $Y$, our strong visual subject, who uses imagery exclusively in learning and here again to an extent and particularly in the mixed order the objective results justify our expectations. In this case, also, it is significant that the super- 
iority decreases as the number of presentations of both words and syllables increases.

Comparing the one, fifteen and forty-five minute intervals between learning periods (Table I.), we obtain no conclusive results except in the $d$, e and $f$ series where there is some uniformity in favor of the one minute interval. One subject, however, finds the fifteen minute interval more favorable. We may say in the main that when the recall comes after the Einprägung, the sooner it comes the better.

When we compare the results for $g$ with those for $d$, e and $f$ we obtain exactly the amount the recall adds to the permanent effect of eight minutes of Einprägung (Table II.). Although there is no uniformity the striking point is that there are only three cases out of the twenty-four in which something is not added and that for $V, W$ and $X$ in the majority of cases the recall adds as much as or more than the added eight minutes of Einprägung in $a, b$ and $c$. As we would expect we find that in the case of $Y$, although the recall adds something, it is less than what the same amount of additional Einprägung adds.

The most significant comparison lies in the figures for the three groups a, b, c; d, e, f and h, i, $j$ (Table III.). In subject $W$, who as has been explained before, makes of this kind of series a mental recitation we find an immense advantage for $\mathrm{h}, \mathrm{i}, \mathrm{j}$ over $\mathrm{a}, \mathrm{b}, \mathrm{c}$ or $\mathrm{d}, \mathrm{e}, \mathrm{f}$. For $V$ and $X$, who use associative links, or rather groupings, to some extent to reinforce their imagery, we find the $h, i, j$ series has a distinct advantage over the $a, b, c$ and $d, e, f$ series, but this advantage is slight. For subject $Y$ who uses little or no associative help but depends on strong visual imagery, we find the $h, i, j$ series is distinctly unfavorable and those series in which the groups are seen the greatest number of times have a great advantage.

Comparing the effect of the mixed order with that of the regular order (Table IV.), we find in $Y^{\prime} s$ results the mixing of the order has an unfavorable effect and this effect increases as the number of actual presentations increases. It is natural in the case of a pronounced visual type such as $Y$, that the more the order of presentation is changed the more confused he 
would become. On the other hand in the a, b, c series of $W$ the mixed order seems to have a slight positive advantage over the regular order. This may be due either to a more strained attention or to practice effect. In the $d, e, f$ series we find a slight advantage in favor of the regular order. In the $h, i$, $j$ series, however, the advantage is overwhelmingly in favor of the regular order. It should be noted again that the procedure in the $h, i, j$ series, which is of such a great advantage to $W$ in the regular order, is impossible in the mixed order.

In studying the results of the tests with $Z$ who, it will be remembered, changes the whole process of learning to suit either the mixed or regular order of presentation, we find that she apparently adapts herself to the mixed order with as little effort as to the regular order.

Above all, the tables show the consistent and characteristic manner in which the memory determines and explains the efficacy of a given factor in the learning process. That the opportunity for recall is of aid in learning we cannot doubt, but the extent of this aid and the explanation of why it is an aid differs widely for different individuals. For some individuals the opportunity to recall is used mainly to reimage, and as we find this is an aid to memory we must agree with Meumann in emphasizing this immediate retrospect as a basis for the explanation of the efficacy of recall. Another individual, however, may discard reimaging entirely and use the recall as a means for an 'inner-speech' recitation, and as we find this of great assistance in learning we must agree with Katzaroff in his emphasis on the value of the 'mental attitude of constantly looking forward.' Again we must note that that extreme type in whose learning processes we find relatively slight traces of association is more benefited by repeated presentation than by the opportunity to reimage, while for the opposite type repeated presentations seem to have little effect. We must go back to the type of the individual to explain the processes and relative efficiency of this factor of recall.

\section{Conclusion.}

We are led then both by our introspective and objective results to conclude : 
I. That the factor of recall is always an aid in the learning process.

2. That when recall comes after the Einprägung of the material, immediate recall is of more value than delayed recall and its value decreases as the delay increases in length.

3. That the recall is of greater value when it is interspersed with the Einprägung.

4. That localization is one of the factors which go to make recall an aid to memory, but that the relative importance of this factor is determined by individual type.

5. That the relative value of recall and Einprägung depends on individual type; that for the individual of strong 'inner-speech' tendency who depends little on immediate reimaging and in recall goes through the same processes that one would in recitation, the recall is of great value and the Einprägung of comparatively little importance, while for the type which depends on immediate reimaging during recall the Einprägung is of relatively greater importance than the recall in proportion as the factor of association is less effective in the learning process. 